\section{British Society of Human Genetics}

Founded in 1996, the British Society of Human Genetics (BSHG) is a forum for professionals working in all aspects of human genetics, from the cutting edge of research to the delivery of genetics services to the population of the United Kingdom. The founding member groups of the BSHG were four existing societies: the Clinical Genetics Society (CGS), the Clinical Molecular Genetics Society (CMGS), the Association of Clinical Cytogeneticists (ACC), and the Association of Genetic Nurses and Counsellors (AGNC). A fifth group, the Cancer Genetics Group, has recently joined.

The membership of the BSHG now exceeds 1300; it includes individuals from a wide spectrum of clinical, laboratory, and research disciplines. Each year the Society holds a 3-day conference that addresses all aspects of human genetics.

The BSHG is governed by a council and a constitution. It has a public policy committee which considers the ethical and social effects of rapidly expanding genetic knowledge and technology. The Society issues statements on various aspects of human genetics and publishes a quarterly newsletter. In addition, its Web site contains information relevant to the membership as a whole and specific information for each of its groups. There are links to other major groups including the European Society of Human Genetics. The BSHG is a member of the International Federation of Human Genetics Societies. A subgroup to consider insurance issues is currently being formed. The Society participates, with clinical and patient groups, in the Joint Committee on Medical Genetics (JCMG), an appropriate forum to inform and influence government policy.

\section{Clinical Genetics Society}

Cedric Carter started the CGS in 1970 and as its first president guided it in the early years. On his retirement, the society honored his contribution to clinical genetics by establishing The Carter Lecture, the first of which was given in 1984 .

The CGS is a particular focus for medical geneticists (medically qualified) and hence includes individuals from all of the regional genetics centers and subspecialties within clinical genetics. Its membership provides data and information necessary to plan the increase in the number of clinical geneticists and includes individuals who sit on boards that address the number of trainees funded in each specialty in the UK. In addition, the CGS gives advice on other matters which will impact the level of referrals to regional genetics services, including proposals for genetic population screening, proposals for antenatal screening, and the impact of testing in private laboratories on UK National Health Service (NHS) practice.

\section{Clinical Molecular Genetics Society}

The CMGS was formed in 1988 following a series of meetings of scientists interested in the diagnostic application of molecular genetics. Its aim is to advance the science of clinical molecular genetics and to further public education. The Society has an interest in promoting the quality of molecular genetics testing in the UK through training, education, research, data collection, and quality schemes. The CMGS includes more than 250 scientists, most of whom work in the NHS laboratories in the regional genetics centers.

This group is involved in basic training; it has a training accreditation board that oversees the basic-level postgraduate training of clinical scientists, provides a control on the facilities programs and management of training in each center, and monitors the progress of each trainee. The training accreditation board awards the exit certificate that allows successful trainees to progress to career-grade jobs. Within the career grade, the Society encourages scientists to continue in training and to enter the examination in molecular genetics offered by the Royal College of Pathologists. As part of this process, the Society has organized a successful series of "self-help" courses, designed to prepare scientists for this examination.

The Society has a research group coordinates a number of collaborative projects designed to tap the large quantity of data held in regional centers and to improve diagnostic testing. In addition, the CMGS began an external quality assessment scheme for molecular genetics about 10 years ago. The scheme is now independent of the Society. It has included laboratories in Europe and hence has influenced the development of the European Quality Accreditation by helping in the formation of the European Molecular Genetics Quality Network supported by the European Commission. The CMGS promotes best practice in molecular genetics testing by calling meetings of scientists from regional centers where they discuss the best techniques, controls, precautions, and interpretation of data for specific diagnostic tests.

In planning for the future, it is important to have good data on the activity nationally and in each center to allow workforce planning and changes in pattern of referral to be taken into account. The CMGS audit committee has collected this information in the standardized format for many years.

Clinical molecular genetics has developed over the past 10 years, so that there is now at least one laboratory of this type in each NHS region. Scientists in these laboratories provide diagnostic services in close collaboration with local clinical genetics services.

\section{Association of Genetic Nurses and Counsellors}

The AGNC is an organization that represents genetic nurses and counselors working within clinical genetics or closely allied research areas. Its aims include providing support for its members, providing forums for scientific and educational meetings, representing the views of the profession, prescribing good standards of clinical practice, liaising and collaborating with colleagues, and providing channels of communication within the genetic counseling profession. In the UK, genetic counselors who have a master's degree in the subject and those with primarily a nursing background work in teams and share 
common professional goals and standards. The AGNC represents practitioners from both groups.

The majority of members are nonmedical professionals whose work involves contact with families or individuals affected by or at risk of a genetic condition. While in many cases members work in regional genetics centers, increasingly those working in allied fields such as oncology and fetal medicine have found that membership is beneficial. The AGNC contributes to the scientific program of the BSHG's 3-day conference, organizes a separate scientific meeting for genetic counselors, and runs specific courses for members.

The AGNC Working Group was convened in 1994 to address issues of education for future and practicing genetic nurses and counselors, and it recently introduced a formal registration system for practitioners in the UK. The Association has responsibility for separate interests in relation to career structure, professional qualifications, code of ethics, and standards of professional competence. It has, however, an overriding interest in developing human genetics in relation to health care in the UK and representing the profession in public.

\section{Association of Clinical Cytogeneticists}

The ACC was formed in 1978 for the purpose of promoting clinical cytogenetics. An active society with more than 450 members, the majority of whom are clinical scientists practicing in the NHS, the ACC holds an annual 2-day scientific conference as well as a number of study days for its members.

Subcommittees include the Education and Training Committee (ETC), which, as well as supporting Higher Specialist Training leading to membership in the Royal College of $\mathrm{Pa}$ thologists (MRCPath), is developing a national training program for cytogenetic technologists. The basic (postgraduate) training program for clinical cytogeneticists is well established and underpinned by residential training courses for "trainers" and "assessors." The ETC collects annual manpower data to inform both the profession and the Department of Health in England.

Collaborative data from UK laboratories collected by working groups initiated by the ACC Scientific Committee have been published in peer-reviewed journals to provide a reliable resource for both the cytogenetic community and interested clinicians.

The Professional Standards Committee is self-explanatory; the new edition of guidelines will be published soon in The Journal of Medical Genetics.

Most recently, a working group comprising representatives of the ACC and the Royal College of Pathologists have undertaken a risk assessment which has led to revised advice on laboratory containment measures for work with tissue samples in clinical cytogenetic laboratories. The advice, pertaining to risk from blood-borne viruses, has been accepted by the Advisory Committee on Dangerous Pathogens and is to be formally published imminently.

\section{Joint Committee on Medical Genetics}

The JCMG includes representatives from the Departments of Health in the UK, the BSHG, the Royal College of Physicians, and the Royal College of Pathologists. Other representatives from allied colleges including Obstetrics \& Gynaecology and Paediatrics hold membership. The Joint Committee has a wide representation and, based on this and the experience of the individuals involved, is able to provide advice to the Department of Health and the government on the commissioning of genetics services. In addition, the JCMG is able to make recommendations on the education required for professionals within clinical genetics, and more broadly within other branches of medicine, to begin to underpin the developments being made in many areas of clinical practice.

\section{Conclusion}

The BSHG is an important focus for the professional groups involved as they apply the developments in medical genetics to clinical practice. The Society has a Web site: www.bshg.org.uk.

Professor Neva Haites Chair, British Society of Human Genetics 